\title{
The computer psychiatrist: How far have we come? Where are we heading? How far dare we go?
}

\author{
HAROLD P. ERDMAN, JOHN H. GREIST, MARJORIE H. KLEIN, \\ JAMES W. JEFFERSON, and CARL GETTO \\ Department of Psychiatry, University of Wisconsin, Madison, Wisconsin 53706
}

\begin{abstract}
The use of computers in psychiatry and psychology is reviewed. It is noted that computers are already being used successfully for consultation, interviewing, and continuing education. Issues related to the usage of computers in mental health are discussed. Guidelines for future work in the area are suggested.
\end{abstract}

As we have commented before (Klein, Greist, \& VanCura, 1975, p. 842), "Part of mankind's difficulty with computers lies in coming to grips with their awesome promises and problems. As Howard Bleich aptly noted, the arrival of the computer represents a "blow to man's ego' that is part of a historical progression. 'When Copernicus proved that the earth was not the center of the universe, but rather a tiny speck, he injured man's pride. When Darwin suggested that we are not specially created, but rather an extension of the animal world, he salted this wounded pride. When Freud taught that we are not the master of our own house, but that we must be content with tiny vignettes of what goes on in our minds, he seared our salted wound' (Bleich, 1973). Many people today are apprehensive about the computer's impact. There is a nostalgic longing for a simpler, more ideal state that gives way only reluctantly to other realities. 'The woods are lovely, dark and deep,/But I have promises to keep,/And miles to go before I sleep/ And miles to go before I sleep' (Frost, 1958)."

Computers, in general, and their growing medical and psychiatric applications have been both roundly praised and vilified. Their growing presence in psychiatry leads proponents and opponents alike to question the rate of their introduction and the quality of their contributions. Some envision a day not far away when computers will talk directly with patients, providing counsel about their problems, and helping patients to manage many of them by themselves (Colby, 1980; Greist, 1980). Maxmen (1976) feels that by the year 2000, we will have entered a "post physician era" in which "corpsmen," selected largely for good interpersonal skills and backed up by an interactive computer consultation program providing tertiary-level information, will have supplanted all physicians except those, like surgeons, whose technical skills require years of repetitive manual training. Weizenbaum and many others who are less widely published but equally vocal decry the intrusion of computers into interpersonal therapies on the grounds that "there are certain sorts of questions which ought not to be asked of computers" (Alexander, 1978, p. 59).
Our brief is that computers have already made substantial contributions to the mental health field, that we are clearly heading toward both broader and deeper use of computers, and that some of the applications presently in the development phase will radically chatlenge present methods of practice and, thereby, raise important ethical questions for the mental health professions.

\section{THE COMPUTER PSYCHIATRIST: CONCEPTUAL ISSUES}

To the extent that the computer is seen as someday displacing the psychiatrist, it will need to perform many of the functions of the psychiatrist: interviewing for data gathering and information giving, consultation to and from other clinicians, continuing medical education for knowledge acquisition, maintaining a personal library, preparation of documents about patients, submitting to quality assurance reviews, and maintaining high ethical standards. These are all functions that may be appropriately required of the computer.

Evaluations of the computer psychiatrist will be difficult to conduct. Although process, outcome, patient and clinician satisfaction, and cost-effectiveness measures are all germane, the complexity of the systems under study means that it will often be difficult to come to quick and firm conclusions about computer applications in psychiatry. Different physicians practice in different ways, even when faced with identical clinical problems. The logical and intuitive processes by which human clinicians practice are poorly understood. Some charlatans, without formal medical training, have maintained longstanding practices and obtained the approval and gratitude of their many patients. Many revered institutions and treatments are widely held to be worthwhile but have not passed formal scientific muster. The medical library, the blood bank, and such time-honored remedies as bland diets for ulcers, bed rest for hepatitis, and digitalis and quinidine are but a few examples. Some fashionable treatments have later been found seriously 
wanting, as the history of cupping, bleeding, purging, and, more recently, the broad-scale use of corticosteroids for arthritis and gastric freezing for ulcer disease have shown.

Often, improvements attributable to technological changes in practice are separately so small that their impact is not statistically significant. Taken together, however, many small changes may yield major improvements in overall system functioning. The complexity of the systems under study often hides these incremental benefits. There are very few penicillins whose effects are so dramatically beneficial that they require little study to gain acceptance into practice.

In many circumstances, the standard of statistically significant improvement has been and will remain inappropriate for many medical procedures and functions, including computers, for which evaluations are sought. Often, the more relevant questions will be whether the computer functions at least as well as the clinician, producing as much improvement and as few side effects and doing so with increased availability and efficiency and reduced cost.

\section{THE COMPUTER PSYCHIATRIST: SPECIFIC APPLICATIONS}

\section{Computer Interviewing}

Work in many different settings covering varied subject matters has clearly shown that computer interviews with psychiatric patients are reliable, accurate, and highly acceptable to most patients (Angle, Ellinwood, \& Carroll, 1978; Card, Nicholson, \& Crean, 1974; Chun, VanCura, Spencer, \& Slack, 1976; Coddington \& King, 1972; Colby, 1973; Coombs, Murray, \& Krahn, 1970; Greist, Gustafson, Stauss, Rowse, Laughren, \& Chiles, 1973, 1974; Greist, Klein, \& VanCura, 1975; Grossman, Barnett, McGuire, \& Swedlow, 1971; Hilf, 1972; Lucas, Mullins, Luna, \& McInroy, 1977; Peckham, Slack, Carr, VanCura, \& Schultz, 1967; Slack, 1971; Slack, Hicks, Reed, \& VanCura, 1966; Slack, Porter, Witschi, Sullivan, Buxbaum, \& Stare, 1976; Slack \& Slack, 1976; Stead, Heyman, Thompson, \& Hammond, 1972; Tompkins, Tompkins, Loder, \& Noonan, 1980; VanCura, 1978; Williams, Johnson, \& Bliss, 1975). Early concerns about the presumed impersonal nature of computer interviews have been refuted by the fact that most patients find the interviewing process enjoyable and the interview content relevant to their problems. In fact, several studies have suggested that as subject matter becomes more sensitive, respondents appreciate the nonhuman interviewer even more (Greist, Klein, \& VanCura, 1973; Greist, VanCura, \& Kneppreth, 1973; Lucas et al., 1977; Slack \& Slack, 1977). Many markedly disturbed patients can be interviewed by computer, and all workers to date have found that $85 \%$ or more of psychiatric inpatients can be interviewed at the time of admission.

\section{Consultation}

Computer consultation programs have already been developed that can provide useful consultation in a variety of areas. Bleich (1974) has shown that an on-line computer program that provides consultation about acid-base and electrolyte abnormalities outperforms 98\% of physicians specializing in the area of nephrology. McDonald (1976) found that computer reminders improved physician compliance with protocols consistent with good medical practice. Shortliffe (1976) has developed a program that provides consultation on selection of antibiotics for treatment of bacterial infection. The National Library of Medicine provides a program on the diagnosis and management of viral hepatatis (Bernstein, Siegel, \& Goldstein, 1980). Programs that compute radiation dose and angles for treatment beams have become virtually standard in the radiation treatment of malignancy. $\bar{D} \mathrm{D}$ Dombal's (1979) system for assisting in diagnosis of abdominal pain has been installed in a number of hospitals in England during the past decade. Results from three hospitals showed that with use of the program, perforated appendix decreased from $29 \%$ to $11 \%$, negative laparotomies decreased from $21 \%$ to $12 \%$, and the discharge rate within $24 \mathrm{~h}$ increased from $18 \%$ to $33 \%$.

In mental health areas, a number of programs have been developed that perform at least as well as clinicians in making important clinical decisions (Sawyer, 1966; Sines, 1970). Williams and Johnson showed that their automated Psychiatric Assessment Unit (PAU), which utilizes direct patient interviews and computer prompts for clinicians, provided useful guidance about issues of admission and management and that patient satisfaction increased and cost of admission process decreased (Johnson, Giannetti, \& Williams, 1976; Johnson \& Williams, 1975; Johnson, Williams, Giannetti, Klingler, \& Nakashima, 1978; Johnson, Williams, Giannetti, \& Schmidt, 1977; Williams et al., 1975). We have evaluated an on-line computer program that makes predictions about risk of suicide attempt that are more accurate than those of clinicians (Greist, Gustafson, Stauss, Rowse, Laughren, \& Chiles, 1973, 1974).

\section{Continuing Education}

Clinicians face the daunting task of remaining current with the expanding knowledge base of their fields. For example, there are now more than 8,000 references to the biological uses of lithium, and the number of citations is increasing by nearly 100 each month. For those who read regularly, there is the very real problem of sorting out which data and opinions to trust. Even in matters of physical properties of basic elements, published reports often differ widely. Patients suffer, thrive, live, and die based on the caliber of evaluations and treatments they receive. Many physicians are proud of their knowledge acquired through years of intense medical school study. Some forget Cowper's admonition: 
"Knowledge and wisdom have ofttimes no connection .... Knowledge is proud that he knows so much. Wisdom is humble that he knows not more."

In contrast with the uncertain and uneven quality of continuing medical education of clinicians, computer programs can be systematically updated as new information becomes available and easily disseminated to all program users. The National Library of Medicine viral hepatitis knowledge base is a prototype of some of the information communication capabilities possible with computers (Bernstein et al., 1980). Techniques were developed for quickly searching the relevant literature (reducing some 16,000 citations in English to a more manageable 329). These were distributed to a panel of 10 experts who were asked to "identify weaknesses, inaccuracies and missing information that needed remedying; consider and suggest changes in overall organization of the knowledge base; suggest changes in individual data elements (rewriting for improved fidelity or clarity, elimination because of unimportance or redundancy, shortening or lengthening, identifying known but missing information to be included from the source documents or from any other sources, and other changes for whatever reasons)" (Bernstein et al., 1980, p. 175). Consensus among experts on initial program displays was reached, and methods for updating the hepatitis knowledge base were developed and implemented so that the knowledge base was at most 3 months behind the published primary literature.

A similar consultation/information transfer model for lithium is being developed under a grant from the National Library of Medicine. Information is immediately available through use of the lithium library (Greist, Jefferson, Coombs, Schou, \& Thomas, 1977). Authors review relevant literature and write segments of the program that are reviewed by other experts in the field. A polished version is entered into an interactive program that permits users to ask questions about many areas of lithium use. The program also asks about questions that remain unanswered after program use, so that gaps in the program can be closed, to the extent that information is available to answer the questions.

While it is at present unclear what presentation format is best (reference citations, short descriptions of key terms, patient-oriented consultations, abbreviation or outline form, full exposition, different vernaculars for different specialties, etc.), the potential for providing inexpensive, up-to-date, high-quality, tertiary-level information any place that electricity and telephones exist (for connecting a terminal to a central computer or for running a microcomputer) is most attractive. Information of this kind, whether presented to clinicians or directly to patients, offers a potential for improving the quality of patient care.

\section{Quality Assurance}

Clinicians are understandably concerned about issues of quality of care. There may be opposition to case review because of the many opportunities for misunder- standing of equivocal results resulting from the best intentions and best practices of ethical clinicians. For those performing at lower levels, the possibilities of censure by peers and loss of livelihood add another level of resistance to peer review. For whatever reason, there is a continuing tension between those requiring and making reviews and those who are under scrutiny.

By contrast, the computer's decision logic and performance are consistent and can be opened to public scrutiny. The computer as interviewer/consultant/ therapist can directly collect data about patient change that can, in turn, be used to evaluate the quality of care provided.

\section{Ethical Considerations}

The mental health professions maintain that they shall provide the highest quality care possible to patients. This requires the application of the most up-to-date diagnostic and treatment methods by suitably trained practitioners at a fair cost. Given equal performance in these regards, the choice between a human or a computer program would logically be left to the patients and the marketplace. When computer programs surpass humans in these areas, the ethics of the profession would dictate use of computers.

We readily concede that some patients might find a computer terminal a dehumanizing medium for dealing with major life issues. But it is equally true that many people find it embarrassing and humiliating to divulge the intimate details of their lives to a stranger, no matter how wrapped in the cloak of professionalism. If it is unethical to make the first type of patient use a computer psychiatrist, is it not equally unethical to deny the second type of patient access to the same computer psychiatrist? And if we could say to the first patient that the computer is at least as effective, and charges $\$ 1 / \mathrm{h}$, rather than $\$ 70 / \mathrm{h}$, might he or she not decide that being unable to afford treatment is what is truly dehumanizing? In our experience, the resistance to computers in the mental health area comes from clinicians, not from patients.

\section{THE COMPUTER PSYCHIATRIST: A PRESENT VIEW}

The computer psychiatrist is presently a toddler, taking its first steps, full of enthusiasm and energy, but uncertain of its prowess and welcome. Several factors, some technical, others social and economic, suggest a short childhood, a precocious adolescence, and an early and productive adulthood. Senescence seems far away.

Costs of computer hardware continue to tumble while computer power increases. Microcomputers are making it feasible for almost anyone to obtain and utilize computers to solve many specific problems they face. Computer languages are growing steadily less cumbersome to use, and elementary school children are able to write meaningful programs. Widespread availability of these tools will produce a several-orders- 
of-magnitude increase in the cadre of individuals using computers to solve problems, in medicine as well as other areas.

The problems of continuing education and unequal distribution of medical services are creating a natural medium for the computer psychiatrist. Up to date because of regular continuing education in the form of reprogramming and willing to go and work anywhere and at all hours either as a consultant to clinicians or in direct interaction with patients themselves, the computer psychiatrist will be a welcome addition not only in rural and urban ghetto areas, but also in the offices of the most prestigious private practitioners.

Although the way forward is not entirely clear, computers are already able to understand a small vocabulary of human speech. The problems involved in oral communication are substantial, but it is reasonable to expect that computers will someday be able to understand natural language and respond to people by speaking with them.

The costs of providing psychiatric services with a computer are already far less than costs of providing them with humans. If one assumes a microprocessor costs $\$ 1,000$ and that a treatment program for phobias might require the patient to keep the computer for 3 months (Raja Ghosh and colleagues, working in London, have developed and are testing such a program), and assuming such a device would have a 5-year useful life, the cost of treating phobic illness with such a device would be $\$ 50 /$ illness as opposed to approximately $\$ 1,000 /$ illness with a psychiatrist.

\section{COMMENTARY}

A number of issues must be considered by those proposing and opposing the use of computer psychiatrists. The intelligent, considered use of inhuman devices is not necessarily inhumane, although it can be. We hold that the opportunities for good far outweigh the risks of bad outcomes. There is a great need at present for workers willing to "train" computer psychiatrists and to assess the effectiveness of these agents.

Issues of confidentiality and privacy can be satisfactorily addressed by computers. Passwords, identification codes, and garbling of sensitive information can all protect data stored in central machines. Small, standalone machines are comparatively safe; their violation would require physical entry to their location and knowledge of their operation, a situation more troublesome for would-be data thieves than rifling a filing cabinet.

There are at least three constituencies for computer psychiatrists: (1) Clinicians may use computer psychiatrists as consultants to help their decision making and also to gather data directly from patients on which the human clinician can make decisions. (2) Patients may find that certain problems are best managed by direct interaction with a computer, rather than through the intermediary of a human clinician. Certainly, the computer can be programmed to provide information and ascertain the level of patient understanding for consent to treatment more consistently and completely than humans do. Computers may also be programmed to assist patients in complying with treatments to which they have consented. (3) Finally, computers may be the actual treating agent, as in the case of various psychotherapies, and may even be licensed to prescribe psychoactive medications.

Psychiatrists often point out to other medical specialists how important it is not to lose sight of the whole person in the process of treating his or her illness. It is as though they are holding up the standard of $3 \mathrm{~h}$ with Osler and $3 \mathrm{~h}$ with Freud in the face of the reality that family practitioners spend an average of $13 \mathrm{~min}$ and internists an average of $18 \mathrm{~min}$ with their patients. It seems likely that a computer psychiatrist will free up some clinician time that could be spent in more direct interactions with patients. Whether this will improve outcomes is uncertain. Computer psychiatrists may improve outcomes by interacting with patients at greater length than human clinicians are willing or able to do, painstakingly working through a treatment contract with an obsessive ritualizer, repeatedly monitoring compliance with important treatments, and sensitively modifying the treatment regimen to correspond better with the individual's life-style. Researchers should be able to move forward more rapidly in answering a variety of clinical questions because of the standardization of data collection and treatment prescription that can result from the use of computer psychiatrists.

Computers may not be the method of choice for most models of intensive insight-oriented psychotherapy. Intuitive processes that are hard or impossible for a human to describe are even harder or more impossible to program. The computer's strength is in its vast and reliable memory and consistency in processing or "thinking." Processes that cannot be reasonably well described by an unambiguous model are not likely to be well simulated by computer. However, the fact is that people with psychological problems are relatively unlikely to receive intensive insight-oriented psychotherapy. They are more likely to speak to a friend or clergyman than to a mental health professional. If they see a doctor, it is more likely to be an internist or other primary-care physician than a psychiatrist. Many psychological problems are more effectively and efficiently treated with modalities other than insight-oriented psychotherapy. In these other modialities, computers may have some advantages over people.

The basic question is whether a computer-assisted psychiatrist, a computer-assisted paraprofessional, or the computer alone is better than the psychiatrist alone or any other human clinician alone. Physicians have in time gained ascendency over priests, barbers, lay practitioners, and chiropractors, and while not all answers in these matters are based on hard science, the best guidance usually comes from some form of systematic evaluation. While these evaluations are 
notoriously difficult to conduct, we see no responsible alternative other than to attempt them. We may be left with a situation in which it will be shown that computer psychiatrists produce outcomes at least as good as those of humans, cause no more harm than humans, are as acceptable to patients, and cost less than human therapies. A gradual accretion of improvements may produce measurable benefits undetectable for single innovations.

We are only beginning to learn how to use the computer. We are at the stage of moving from silent to talking films, from continuous motion to stop action for sports on TV. We need the equivalent of John Fowles, John Updike, Kurt Vonnegut, and Garry Wills as writers for computer displays. We need far better understanding of the person-machine interface (Fox, 1977) and of medical systems themselves (Fox, 1979). It is very difficult to introduce logical and systematic machines into use in idiosyncratic practices. Where structure and orderly processes are already in place, as in laboratories and fiscal operations, the computer is well established. By contrast, we are in a protoscientific era with regard to understanding clinical systems, and our relative ignorance is a handicap in applying computers to clinical problems.

There is also the issue of whether or not to stop with statistical and probabilistic diagnoses and recommendations. Even though these decision methods outperform clinicians in almost every comparison, it is possible to go beyond these statistical approaches to include more sophisticated and sometimes subtle suggestions for evaluation and management. There are times when simple tree-branch logic may surpass statistical logic, and a combination of statistical and clinical judgment may surpass either alone.

For computer psychiatrists to make an appropriate contribution to psychiatric care, the computer systems will need to be well integrated into clinical settings. Total systems designs are not understood at this time, and attempts to force comprehensive computer systems onto clinical settings are uniformly met with great and often justified resistance. It seems to us that the best strategy for introducing computers into psychiatry is to work with small machines and to directly involve the very individuals who will ultimately use the computers in the design and evaluation of the programs. As separate programs become successful in discrete areas, they can be merged into a more comprehensive system, taking advantage of the marked flexibility of currently available programming languages. Hardware, computer languages, processing algorithms, computer terminals, and vernaculars of interactions with clinicians and patients will be different from area to area, just as they are with human specialists. The model of different specialty training programs seems relevant at this stage in our understanding and development of computer psychiatrists. Computer programs to perform different functions will require different programming or "training" periods.
To date, computers have been successful in processing data about narrow clinical areas with accuracy and precision surpassing that of human clinicians. As Blois (1980) points out, the initial triage problem is immense, and the development of a comprehensive computer psychiatrist capable of screening patients presenting the full spectrum of possible problems must await a better fundamental understanding of the domain of psychiatric problems and the processes by which clinicians discriminate among the several possible avenues of further evaluation and management.

It is already clear that computers are playing important roles in psychiatry. Their evolution into a form in which they perform the functions of a computer psychiatrist is gaining speed, and we believe the next 2 decades will present the profession with important issues in assimilation of this new tool. There will be many difficult personal and professional ethical dilemmas as well. If Bleich (1973) is right in his progression of traumas to the human spirit, it may be fair to conclude with a quote from Darwin, the second gauntleteer in this line. At the close of The Origin of Species, he wrote: "Although I am fully convinced of the truth of the views given in this volume ...., I by no means expect to convince experienced naturalists whose minds are stocked with a multitude of facts all viewed, during a long course of years, from a point of view directly opposite to mine. ... A few naturalists, endowed with much flexibility of mind ... may be influenced by this volume. But I look with confidence to the future, to young and rising naturalists, who will be able to view both sides of the question with impartiality" (Darwin, 1859 , p. 479).

\section{REFERENCES}

Alexander, G. Terminal therapy. Psychology Today, September 1978 , pp. $50-60$.

angle, H. V., Ellinwood, E. H., \& Carroll, J. Computer interview problem assessment of psychiatric patients. In F. H. Orthner (Ed.), Proceedings: The Second Annual Symposium on Computer Application in Medical Care. Washington, D.C: Institute of Electrical and Electronic Engineers, 1978.

Bernstein, L. M., Siegel, E. R., \& Goldstein, C. M. The hepatitis knowledge base. Annals of Interval Medicine, 1980, 93, 169-181.

BLEICH, H. L. The computer as consultant. New England Journal of Medicine, 1973, 223, 308-312.

BLEICH, H. L. Automated instructional programs for advanced medical education. In Stacy, R. W., Waxman, B. D. (Eds.), Computers in biomedical research (Vol. 4). New York: Academic Press, 1974.

Buors, M. S. Clinical judgment and computers. New England Journal of Medicine, 1980, 303, 192-197.

Card, W. I., Nicholson, M., \& Crean, G. P. A comparison of doctor and computer interrogation of patients. International Journal of Biomedicine and Computers, 1974, 5, 175-187.

Chun, R. W. M., VanCura, L. J., Spencer, M., \& Slack, W. V. Computer interviewing of patients with epilepsy. Epilepsia, 1976, 17, 371-375.

Codpinaton, R. D., \& King, T. L. Automated history taking in child psychiatry. American Journal of Psychiatry, 1972, 129, 276-282. 
Colby, K. M. The rationale for computer based treatment of language difficulties in non-speaking autistic children. Psychiatry, 1973, 3, 254-260.

ColBY, K. M. Computer psychotherapists. In J. B. Sidowski, J. H. Johnson, \& T. A. Williams (Eds.), Care delivery systems. Norwood, N.J: Ablex, 1980.

Coombs, G. J., Murray, W. R., \& Krahn, D. W. Automated medical histories: Factors determining patient performance. Computers in Biomedical Research, 1970, 3, 178-181.

Darwin, C. On the origin of species. London: J. Murray Publ., 1859.

DeDombal, F. T. Computers and the surgeon: A matter of decision. The Surgeon, 1979, 33, 57.

Fox, J. Medical computing and the user. International Journal of Man-Machine Studies, 1977, 9, 669-686.

Fox, J. Development of hospital computing. Journal of the Royal Society of Medicine, 1979, 72, 425-431.

Frost, R. Stopping by the woods on a snowy evening. In L. Untermeyer (Ed.), Modern American poetry. New York: Harcourt Brace \& World, 1958.

GreIst, J. H. Computer therapy. In R. Herink (Ed.), The psychotherapy handbook. New York: New American Library, 1980.

Greist, J. H., Gustafson, D. H., Stauss, F. F., Rowse, G. L., Laughren, T. P., \& Chiles, J. A. A computer interview for suicide risk prediction. American Journal of Psychiatry, 1973, 130, 1327-1332.

Greist, J. H., Gustafson, D. H., Stauss, F. F., Rowse, G. L., Laughren, T. P., \& Chiles, J. A. Suicide risk prediction: A new approach. Life Threat Behavior, 1974, 4, 212-223.

Greist, J. H., Jefrerson, J. W., Coombs, A. M., Schou, M., \& Thomas, M. A. The lithium librarian-An international index. Archives of General Psychiatry, 1977, 34, 456.

Greist, J. H., Klein, M. H., \& VanCura, L. J. A computer interview for psychiatric patient target symptoms. Archives of General Psychiatry, 1973, 29, 247-253.

Greist, J. H., Klein, M. H., VanCura, L. J., \& Erdman, H. P. Computer interview questionnaires for drug use/abuse. In D. J. Lettieri (Ed.), Predicting adolescent drug use: $A$ review of issues, methods and correlates. Washington, D.C: U.S. Government Printing Office, 1975.

Greist, J. H., VanCura, L. J., \& Kneppreth, N. P. A computer interview for emergency room patients. Computers in Biomedical Research, 1973, 6, 257-265.

Grossman, J. H., Barnett, G. O., McGuire, M. T., \& Swedlow, D. B. Evaluation of computer-acquired patient histories. Journal of the American Medical Association, 1971, 215, 1286-1291.

Hilf, F. D. Partially automated psychiatric interviewing-A research tool. Journal of Nervous and Mental Disorders, 1972, $155,410-418$.

Johnson, J. H., Giannetri, R. A., \& Williams, T. A. Computers in mental health care delivery: A review of the evolution toward interventionally relevant on-line processing. Behavior Research Methods \& Instrumentation, 1976, 8, 83-91.

Johnson, J. H., \& Williams, T. A. The use of on-line computer technology in a mental health admitting system. American Psychologist, 1975, 30, 388-390.

Johnson, J. H., Williams, T. A., Giannetti, R. A., Kuingler, D. E., \& Nakashima, S. R. Organizational preparedness for change: Staff acceptance of an on-line computer-assisted assessment system. Behavior Research Methods \& Instrumentation, 1978, 10, 186-190.

Johnson, J. H., Williams, T. A., Giannetti, R. A., \& SchмidT, L. J. Strategies for the successful introduction of computer technology in a mental health care setting: The problem of change. National Computer Conference Exposition Proceedings, 1977, 46, 55-58.

Klein, M. H., Greist, J. H., VanCura, L. J. Computers and psychiatry: Promises to keep. Archives of General Psychiatry, 1975, 32, 837-843.

Lucas, R. W., Mullins, P. J., Luna, C. B. X., \& McInroy, D. C. Psychiatrists and a computer as interrogators of patients with alcohol-related illnesses: A comparison. British Journal of Psychiatry, 1977, 131, 160-167.

MAXMEN, J. S. The post physician era: Medicine in the twentyfirst century. New York: Wiley, 1976.

McDonald, C. J. Protocol-based computer reminders, the quality of care and the non-perfectability of man. New England Journal of Medicine, 1976, 295, 1351-1355.

Peckham, B. M., Slack, W. V., Carr, W. F., VanCura, L. J., \& Schultz, A. E. Computerized data collection in the management of uterine cancer. Clinical Obstetrics and Gynecology, $1967,10,1003$.

SAWYER, J. Measurement and prediction, clinical and actuarial. Psychological Bulletin, 1966, 66, 178-200.

Shorthiffe, E. H. Computer-based medical consultations. New York: MYCIN Elsevier, 1976.

Sines, J. O. Actuarial versus clinical prediction in psychopathology. British Journal of Psychiatry, 1970, 116, 129-144.

SLACK, W. V. Computer-based interviewing system dealing with nonverbal behavior as well as keyboard responses. Science, 1971, 171, 84-87.

Slack, W. V., Hicks, G. P., Reed, C. E., \& VanCura, L. J. A computer based medical history system. New Englana Journal of Medicine, 1966, 274, 194-198.

Slack, W. V., Porter, D., Witschi, J., Sullivan, M., Buxbaum, R., \& Stare, F. J. Dietary interviewing by computer. Journal of the American Diet Association, 1976, 69, 514-517.

Slack, W. V., \& Slack, C. W. Talking to a computer abou emotional problems: A comparative study. Psychotherapy Theory, Research and Practice, 1977, 14, 156-164.

Stead, W. W., Heyman, A., Thompson, H. K., \& Hammond W. E. Computer-assisted interview of patients with functiona headache. Archives of Internal Medicine, 1972, 129, 950-955

Tompkins, B. M., Tompkins, W. J., Loder, E., \& Noonan A. F. A computer-assisted preanesthesia interview: Value of a computer-generated summary of the patient's historical infor mation in the preanesthesia visit. Anesthesia and Analgesia Current Research, 1980, 59, 3-10.

VanCurA, L. J. A self administered health hazard appraisal In F. H. Orthner (Ed.), Proceedings: The Second Annua Symposium on Computer Application in Medical Care Washington, D.C: Institute of Electrical and Electronic Engineers, 1978.

Williams, T. A., Johnson, J. H., \& Bliss, E. L. A computer assisted psychiatric assessment unit. American Journal o Psychiatry, 1975, 132, 1074-1076. 